\title{
Updating \\ Interconnection Screens \\ for PV System \\ Integration
}

Michael Coddington, Barry Mather,

and Benjamin Kroposki

National Renewable Energy

Laboratory

Kevin Lynn and Alvin Razon

U.S. Department of Energy

Abraham Ellis and Roger Hill

Sandia National Laboratories

Tom Key, Kristen Nicole, and Jeff Smith

Electric Power Research Institute 


\title{
Updating Interconnection Screens for PV System Integration
}

\author{
Michael Coddington, Barry Mather, and \\ Benjamin Kroposki \\ National Renewable Energy Laboratory \\ Kevin Lynn and Alvin Razon \\ U.S. Department of Energy \\ Abraham Ellis and Roger Hill \\ Sandia National Laboratories \\ Tom Key, Kristen Nicole, and Jeff Smith \\ Electric Power Research Institute
}

Prepared under Task No. SS12.1310

NREL is a national laboratory of the U.S. Department of Energy, Office of Energy Efficiency \& Renewable Energy, operated by the Alliance for Sustainable Energy, LLC.

Technical Paper

NREL/TP-5500-54063

February 2012

Contract No. DE-AC36-08GO28308 


\section{NOTICE}

This report was prepared as an account of work sponsored by an agency of the United States government. Neither the United States government nor any agency thereof, nor any of their employees, makes any warranty, express or implied, or assumes any legal liability or responsibility for the accuracy, completeness, or usefulness of any information, apparatus, product, or process disclosed, or represents that its use would not infringe privately owned rights. Reference herein to any specific commercial product, process, or service by trade name, trademark, manufacturer, or otherwise does not necessarily constitute or imply its endorsement, recommendation, or favoring by the United States government or any agency thereof. The views and opinions of authors expressed herein do not necessarily state or reflect those of the United States government or any agency thereof.

Available electronically at http://www.osti.gov/bridge

Available for a processing fee to U.S. Department of Energy and its contractors, in paper, from:

U.S. Department of Energy

Office of Scientific and Technical Information

P.O. Box 62

Oak Ridge, TN 37831-0062

phone: 865.576 .8401

fax: 865.576 .5728

email: mailto:reports@adonis.osti.gov

Available for sale to the public, in paper, from:

U.S. Department of Commerce

National Technical Information Service

5285 Port Royal Road

Springfield, VA 22161

phone: 800.553 .6847

fax: 703.605.6900

email: orders@ntis.fedworld.gov

online ordering: http://www.ntis.gov/help/ordermethods.aspx 


\section{Acknowledgements}

The National Renewable Energy Laboratory (NREL) would like to acknowledge co-authors Kevin Lynn, U.S. Department of Energy (DOE); Alvin Razon, SRA International Inc. (contractor-DOE); Abraham Ellis and Roger Hill, Sandia National Laboratories; and Tom Key, Kristen Nicole, and Jeff Smith, Electric Power Research Institute for their expert contributions to this paper.

Additionally, the authors would like to thank the following reviewers for their comments on various drafts:

Josh Hambrick and Thomas Basso, NREL; Michael Sheehan, Interstate Renewable Energy Council; Jason Keys and Kevin Fox, Keys and Fox, LLP; Tom Bialek, William Torre, Jose Carranza, and Ali Yari, San Diego Gas and Electric; Chase Sun, Jonathan Sykes, John Carruthers, Matthew Helig, Michael Jensen, Joan Dellavalle, and Harjeet Gill, Pacific Gas and Electric; Russell Neal, Brandon Tolentino, Roger Salas, Robert Yinger, and Leanne Swanson, Southern California Edison; David Brown and Gilbert Angeja, Sacramento Municipal Utility District; Daniel Adamson, Solar Energy Industries Association; Rachel Peterson, Jaclyn Marks, and the technical staff at California Public Utility Commission.

Finally, we thank Connie Komomua, NREL, for her editing support. 


\section{Contents}

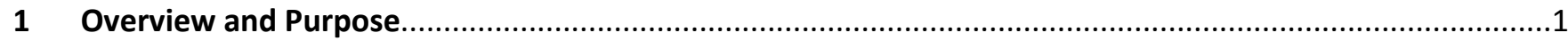

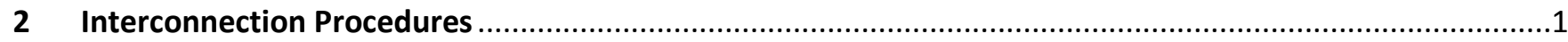

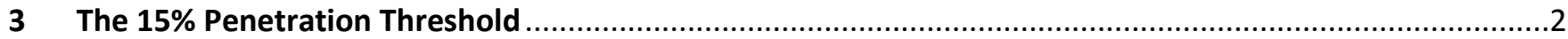

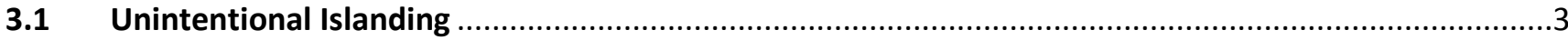

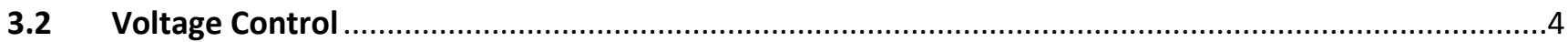

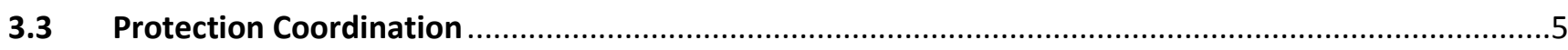

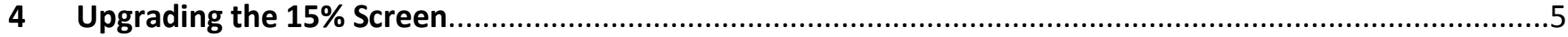

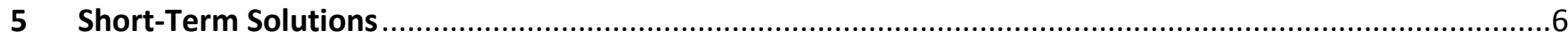

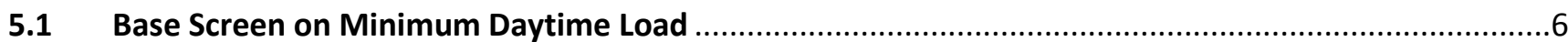

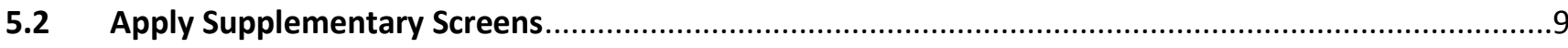

5.3 Utility Identified Zones of Penetration Levels ..................................................................... 12

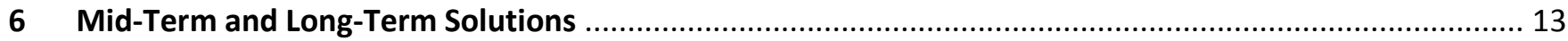

6.1 Develop Higher Accuracy Screening Metrics and Formulas ........................................................... 13

6.2 Upgrade Distribution Circuit Design for PV-Hosting Applications ................................................ 14

6.3 Deploy Inverters with Advanced Functions ............................................................................. 15

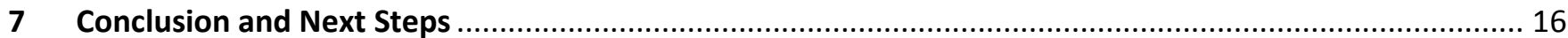




\section{Overview and Purpose}

Solar photovoltaics (PV) is the dominant type of distributed generation (DG) technology interconnected to electric distribution systems in the United States and deployment of PV systems continues to increase rapidly. In states such as California, Hawaii, and New Jersey alone, the number of new PV interconnection applications is in the thousands each year. Considering the rapid growth and widespread deployment of PV systems embedded in United States electric distribution grids, it is important that interconnection procedures be as streamlined as possible to avoid unnecessary interconnection studies, costs, and delays.

Since many PV interconnection applications involve high penetration scenarios, the process needs to allow for a sufficiently rigorous technical evaluation to identify and address possible system impacts. Existing interconnection procedures are designed to balance the need for efficiency and technical rigor for all DG. However, there is an implicit expectation that those procedures will be updated over time in order to remain relevant with respect to evolving standards, technology, and practical experience. Modifications to interconnection screens and procedures must focus on maintaining or improving safety and reliability, as well as accurately allocating costs and improving expediency of the interconnection process.

The purpose of this paper is to evaluate the origins and usefulness of the capacity penetration screen, offer short-term solutions which could effectively allow fast-track interconnection to many PV system applications, and consider longer-term solutions for increasing PV deployment levels in a safe and reliable manner while reducing or eliminating the emphasis on the penetration screen. Short-term and longer-term alternatives approaches are offered as examples; however, specific modifications to screening procedures should be discussed with stakeholders and must ultimately be adopted by state and federal regulatory bodies.

\section{Interconnection Procedures}

Interconnection procedures vary depending on state or federal jurisdiction, and implementation practices vary by utility system. In May 2005, the Federal Energy Regulatory Commission (FERC) adopted small generator interconnection procedures for distributed energy resources up to 20 megawatts in capacity. The FERC document titled Small Generator Interconnection Procedures (SGIP) applies to facilities that fall under federal jurisdiction, those that participate in and interconnect with wholesale market transactions with "facilities that are already subject to the transmission provider's Open Access Transmission Tariff (OATT) at the time the interconnection request is made." ${ }^{1}$ The FERC SGIP was also intended to be a "model rule" for consideration by state public utility commissions who commonly regulate distribution level interconnection procedures.

Most procedures allow for expedited interconnection without additional technical studies if the proposed interconnection passes a series of technical screens. If a proposed interconnection fails one or more of the screens, supplemental interconnection studies may be required before it can proceed to interconnection. These supplemental studies may only add a few weeks or months to the interconnection approval process, but they have a

\footnotetext{
${ }^{1}$ FERC Order 2006 Paragraph 5, Page 4 http://www.ferc.gov/eventcalendar/files/20050512110357-order2006.pdf.
} 
significant impact on the time, cost, and uncertainty of the proposed project. And for many utilities and PV developers, the potential impacts from PV are not clearly understood and the supplemental studies are not well defined.

\section{The 15\% Penetration Threshold}

In 1999, before the FERC SGIP was established, the California Public Utilities Commission (CPUC) issued an order instituting a rulemaking to address interconnection standards for devices to the electric grid in California. The order resulted in the reform of CPUC Rule 21, which identified screens that allowed low-impact generators to be interconnected relatively quickly and made the review process more efficient for small, low-impact generation at low penetration levels. During the reformation of CPUC Rule 21, a 15\% threshold was established to identify situations where the amount of DG capacity on a line section exceeds $15 \%$ of the line section annual peak load. The $15 \%$ threshold was then adopted in the FERC SGIP and is used by most states as a model for developing their interconnection procedures. Under most applicable interconnection screening procedures, penetration levels higher than $15 \%$ of peak load trigger the need for supplemental studies.

The $15 \%$ threshold is based on a rationale that unintentional islanding, voltage deviations, protection miscoordination, and other potentially negative impacts are negligible if the combined DG generation on a line section is always less than the minimum load.

There are three commonly used measures to describe penetration levels: instantaneous, energy, and capacity. Instantaneous penetration ${ }^{2}$ is defined as the output power of total DG on a circuit divided by the circuit load at any particular instance in time. This value will change over time depending on the load conditions and power output from DG. Energy penetration is the ratio of energy generated on a circuit divided by energy consumed by load over a specific period of time (typically one year). Capacity penetration is defined as the nameplate capacity of the combined DG on a circuit divided by the peak annual load on that circuit. The capacity penetration threshold is expressed in terms of peak load, as opposed to the intended metric (minimum load) because peak load data is tracked and accessible to utilities.

Figure 1 summarizes the FERC SGIP initial review process, from which many states have adopted the same or a similar set of screens. The first screen examines total penetration by capacity, defined as the ratio of total DG capacity to the peak load, and determines whether penetration level is less than $15 \%$ of the line-section peak load. This $15 \%$ threshold applies to radial distribution circuits, which is the most common type of distribution circuit with interconnected PV systems. For typical distribution circuits in the United States, minimum load is approximately $30 \%$ of peak load. ${ }^{3}$ The actual ratio varies widely depending on many factors such as the type of load served. Based on this generalization, the $15 \%$ penetration level (one half of the 30\%) was selected as a conservative penetration level for general screening purposes.

\footnotetext{
2 Load data is often tracked in intervals of 15 or 30 minutes by utilities, so the "instantaneous" is actually more discrete in nature.

${ }^{3}$ This is considered a rule of thumb for electric distribution engineers and is based on observation that the minimum load is, on average, approximately $30 \%$ of the peak annual load.
} 


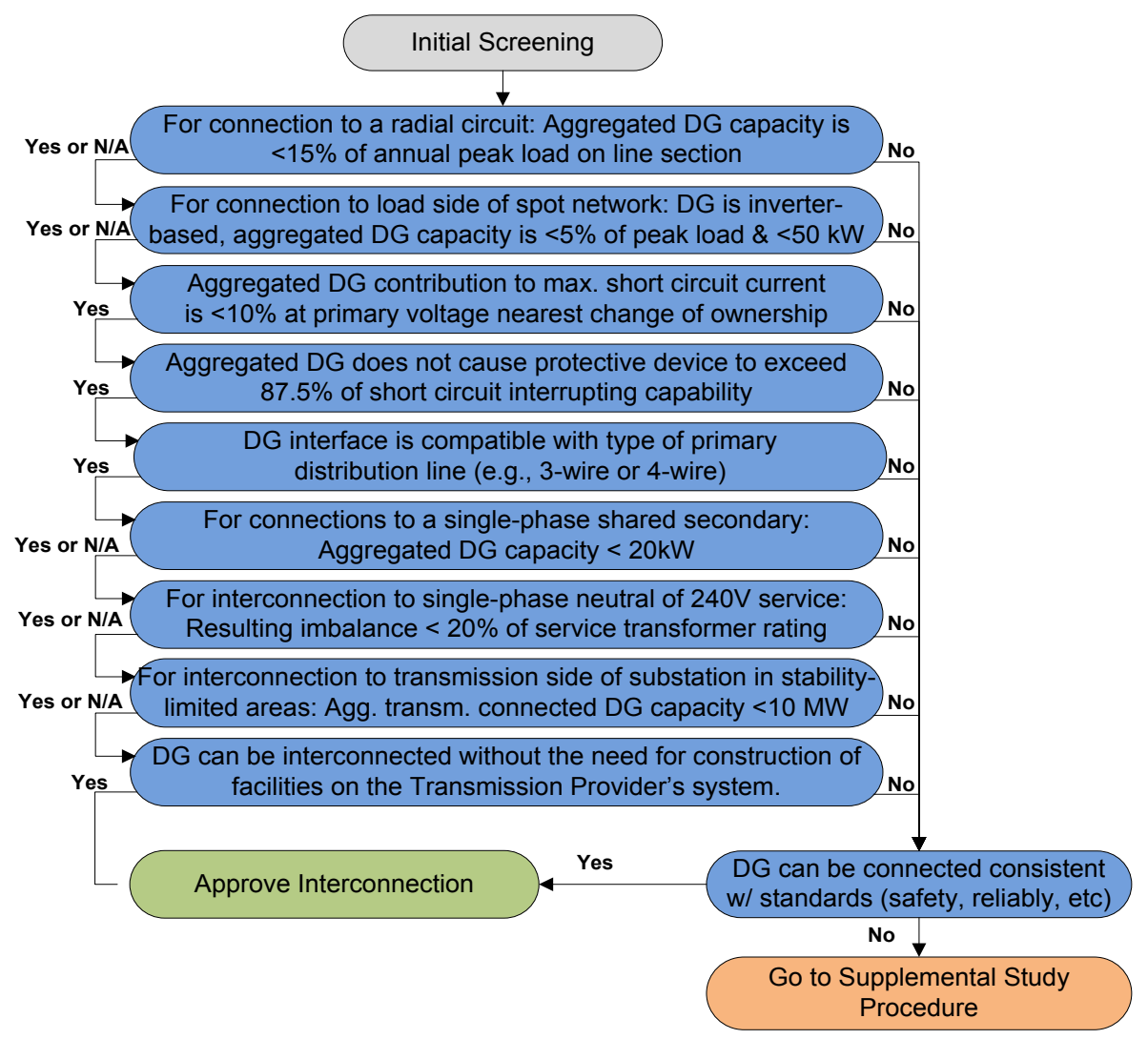

Figure 1 - FERC SGIP initial review screens summarized

Originally, the purpose of the $15 \%$ screen was to identify situations where the amount of DG penetration may be large enough to sustain an unintentional island, a condition deemed hazardous to utility personnel and possibly damaging to loads. The threshold was also intended as a "catch all" rule to eliminate other possible problems related to voltage control and system protection. There is considerable debate on whether or not more efficient and appropriate screening criteria can be used, especially in light of the fact that that this screen, more than any other, triggers the need for additional studies. In addition, PV systems have unique technical characteristics that, if taken into account, could lead to a more efficient and effective screening procedure. The following sections discuss these PV characteristics and how the current $15 \%$ screen does not always take them into account.

\subsection{Unintentional Islanding}

Risks from unintentional islanding conditions include unacceptable voltage and frequency levels, transient over-voltage conditions, equipment damage, and operational safety concerns. Grid-connected PV inverters have anti-islanding features built into the controls, and are required to be "certified" for the intended use, meaning that they must have UL $1741^{4}$ certification and meet IEEE 1547 grid compatibility requirements. The possibility of

${ }^{4}$ Information on UL 1741 can be found at http://ulstandardsinfonet.ul.com/scopes/1741.html. 
PV inverters unintentionally islanding is very low because UL 1741-listed inverters use anti-islanding algorithms that detect and drop off line within two seconds after an island is formed.

Unintended islanding remains a particular concern when PV and synchronous generators, such as diesel generators or other DG without anti-islanding features, are connected onto the same line section. These machines may mimic normal grid conditions, causing the PV inverters to stay online.

Another significant utility concern is that the unintentional islanding test in UL 1741 is conducted on only a single inverter at a time. For this reason, some argue that multiple inverters could interfere with each other in such a way as to increase the chances that an unintentional island not be detected. While it is not possible to reduce the risk to zero, the reality is that the risk is extremely low, considering all the factors that need to be concurrently present. The most compelling substantiation is that incidents of unintentional islanding are extremely rare in actual field experience despite numerous examples of high penetration scenarios that exist. While a complete discussion of anti-islanding techniques is outside the scope of this paper, there are some simple concepts that can be incorporated in screening procedures to assess the risk of unintentional islanding. ${ }^{5}$

\subsection{Voltage Control}

A major concern and most commonly reported problem associated with high penetration of $\mathrm{PV}$ on distribution feeders is high steady-state voltage. When power is injected into a part of the electric power system that normally serves load the voltage at that location tends to increase. With higher penetration, higher voltages are expected along a feeder. The voltage effect depends on the feeder characteristics (voltage rating, conductor size, conductor material, overhead or underground) and location of PV along the feeder. Because feeders are often designed to be higher ampacity (thus lower impedance), thus "stiffer6", near the substation, and because the substation will often contain voltage control equipment, the impact from PV on steady-state voltage is generally lessened as the distance to the substation is decreased. Conversely, as PV systems are located longer distances from the substation, the stiffness often decreases and the potential for high voltages becomes greater (especially during periods of light load such as weekend days).

Figure 2 illustrates the possible impact of PV on steady-state voltage. On a circuit with no DG present (red line) the voltage along the feeder decreases as distance from the substation increases. If PV power injected into the circuit (blue line) is high enough, the voltage will increase, potentially taking the voltage above normal operational conditions $(5 \%$ above nominal). PV located close to the substation can also affect steady-state voltage regulation by "masking" part of the load and thus interfering with load-controlled voltage regulation equipment. In either case, the net result is that high penetration would make it more challenging to maintain acceptable voltage regulation. It should be kept in mind that $15 \%$ penetration threshold, by itself, is not a good indicator of when steady-state high voltage are likely to occur.

\footnotetext{
${ }^{5}$ S. Gonzalez, M. R, A. Fresquez, M. Montoya, and N. Opell, "Multi-Inverter Utility Interconnection Evaluations", Proc, 37th IEEE PVSC, 2010.

"A "stiff" location on a feeder would typically have a lower than average impedance and larger conductor capable of serving many megawatts of power to utility customers.
} 


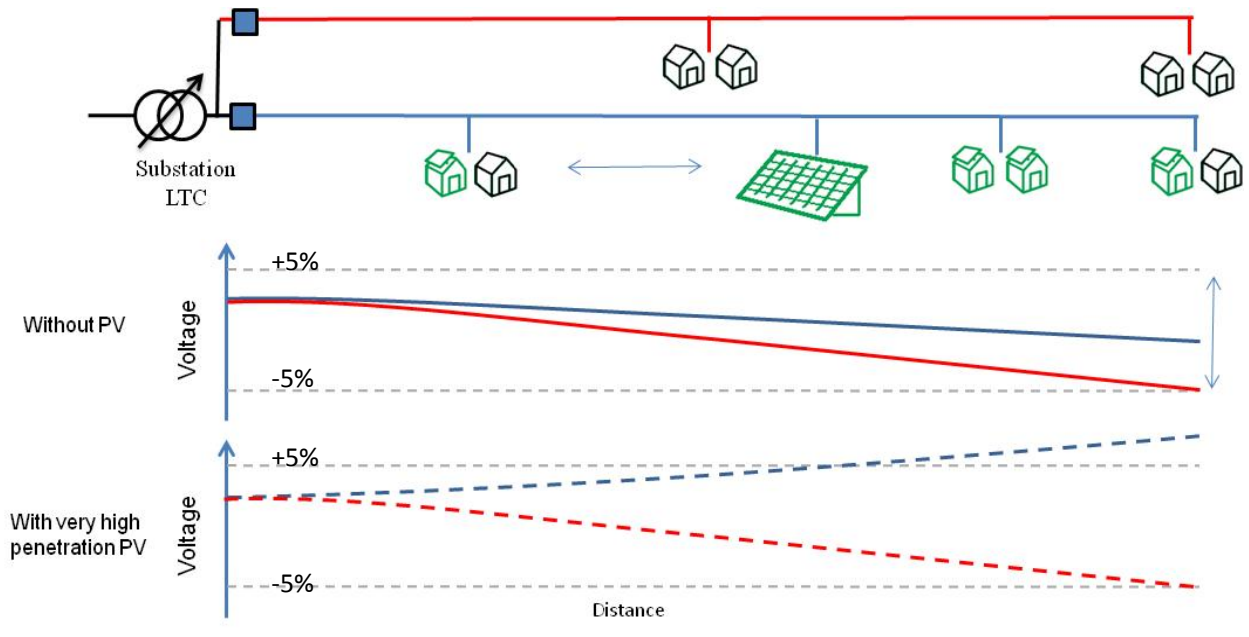

Figure 2 - Example of voltage rise problem for a high penetration scenario

Similar to steady-state voltage issues, if the PV system is located further from the distribution substation, PV output variability can result in significant voltage variability. Possible consequences are poor voltage regulation and increased cycling and stress on voltage control equipment (line regulators and switched capacitor banks) leading to more frequent and costly maintenance. A series of case studies on high penetration circuits is being developed and is planned for publication in $2012 .{ }^{7}$

\subsection{Protection Coordination}

A PV inverter's contribution to fault current is limited and not as likely to cause protection problems $^{8}$ as rotating machines; however, screening procedures routinely check for coordination and grounding compatibility. In some PV inverter installations, an effectively grounded neutral is required to reduce the potential for transient overvoltage during unbalanced system faults. Multiple ground sources can increase ground current contribution and affect the sensitivity of ground current protection functions at the substation.

\section{Upgrading the $15 \%$ Screen}

During review of PV interconnection requests in regions with a high level of PV deployment, the $15 \%$ interconnection screen often triggers the need for supplemental studies. In many cases, even when PV penetration is substantially above 15\%, the supplemental review does not identify any necessary system upgrades. There are many circuits across the United States and Europe with PV penetration levels well above 15\% where system performance, safety, and reliability have not been materially affected. ${ }^{9}$

\footnotetext{
${ }^{7}$ NREL case studies on high penetration distribution circuits to be published 2012.

${ }^{8}$ Keller, J., Kroposki, B. (2010). Understanding Fault Characteristics of Inverter-Based Distributed Energy Resources. NREL Report No. TP-550-46698.

${ }^{9}$ M. Braun et al. "Is the Grid Ready to Accept Large Scale PV Deployment? - State of the Art, Progress and Future Prospects", Submitted to Progress in PV, to be published in 2012.
} 
These observations offer some indication that the existing $15 \%$ screen is conservative and is not an accurate method of determining the hosting capability (ability to add more PV without system upgrades) of a particular feeder. The following short-term, mid-term, and long-term approaches may be considered as possible steps to improve interconnection procedures for distribution-connected PV systems.

\section{Short-Term Solutions}

Inverter-based PV has unique technical characteristics that reduce the impacts on grid operations. Unlike other DG resources, the output pattern of PV is strictly diurnal (active in daytime). The grid-PV interface is an electronic inverter with adjustable settings and short circuit current much lower than synchronous generators of the same output rating. PV inverters are designed to comply with IEEE 1547 standards and UL-1741 certification without the need for external protection or controls. By taking into account these technical characteristics, it is possible to refine screening procedures to be more efficient and effective, substantially reducing interconnection process time and effort for PV deployment without compromising safety and reliability of the interconnected distribution system. Several possible approaches could be undertaken in the short term to improve screening procedures for distribution-connected PV systems.

There are three conceptual examples discussed in this section. The first approach is to include a PV-specific screening criterion that utilizes the minimum daytime load instead of the absolute minimum load. The second approach is to apply additional screens to identify possible technical issues, regardless of penetration level. Finally, the third approach is to increase the penetration levels by identifying zones of higher penetration based on the utility distribution feeder configuration and location of substations.

\subsection{Base Screen on Minimum Daytime Load}

The fact that PV generation has a strictly daytime pattern is significant considering that voltage impacts tend to be greater during periods of highest instantaneous penetration. By the time PV systems are producing a substantial amount of power, loads are well above their nightly lows on most feeders. Therefore, it makes sense to consider minimum daytime load as a technical screening criterion. For example, a screen may set a threshold at minimum daytime load, where daytime is defined as the period between 10:00 a.m. and 2:00 p.m. A simple modification of the SGIP screening criteria to implement this PV-specific screening criterion is depicted in Figure 3. If the PV system passes the additional screen it passes the penetration screen. 


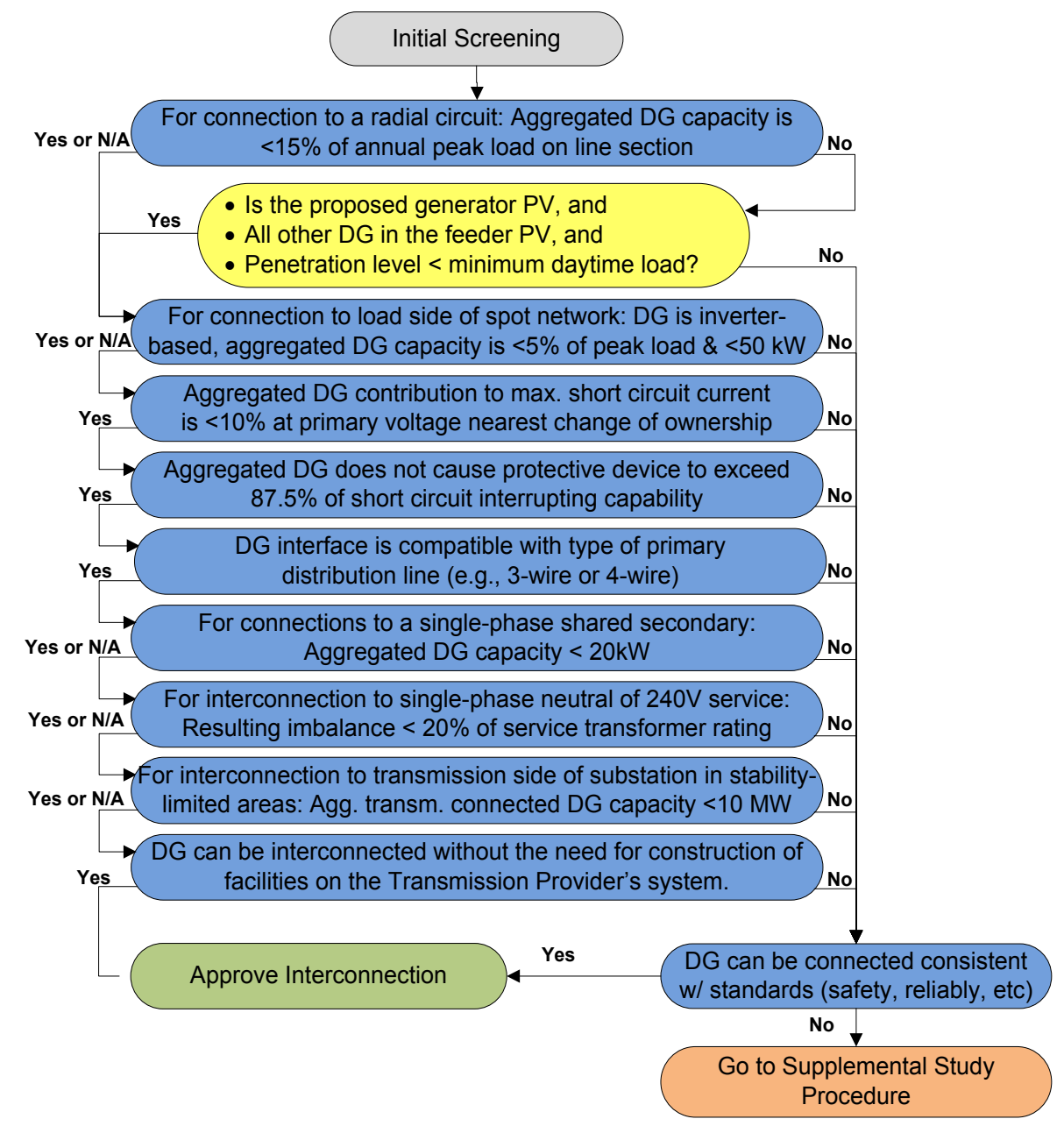

\section{Figure 3 - Modified SGIP screens to address PV interconnection based on minimum daytime load}

If actual historical data is available, load data in areas of interest could be analyzed to establish factors that relate minimum daytime load levels to peak load levels. Some utilities already use minimum daytime load as a screening criterion and have determined these load levels for their service territory. Figure 4 illustrates an example circuit where the annual minimum daytime load is significantly higher than the minimum 24-hour load. Figure 5 shows the comparative ratios of minimum load to peak load, and minimum daytime load to peak load, for 500 residential and commercial feeders in a southwest U.S. city. The figure shows the percentage of the feeders which have a minimum to peak load ratio between zero and $20 \%, 20 \%-30 \%, 30 \%-40 \%$, and $40 \%-50 \%$ based on minimum daytime load (10 a. m. 2 p.m.) and minimum 24-hour load.

It may be difficult to establish minimum daytime load unless reliable historical data is available; however, most utilities now have access to feeder minimum load and feeder peak load data via Supervisory Control and Data Acquisition (SCADA) systems. If SCADA data is unavailable, minimum daytime load can be estimated based on standard load profiles for various customer classes that many utilities maintain and update on an annual basis. ${ }^{10}$ It

\footnotetext{
${ }^{10}$ See http://www.sce.com/AboutSCE/Regulatory/loadprofiles/2011loadprofiles.htm.
} 
should be noted that historical minimum loads are no guarantee of future minimum load levels, which creates some uncertainty and need for better communication between DG and the utility operations and control, especially when DG is in the megawatt scale. And sections of distribution circuits are frequently switched onto adjacent circuits, which adds to the uncertainty of minimum and peak load values, and there are times when large loads may be offline. Load variability and circuit segment switching must be considered by utility planning engineers when determining minimum daytime load of sections of feeders.

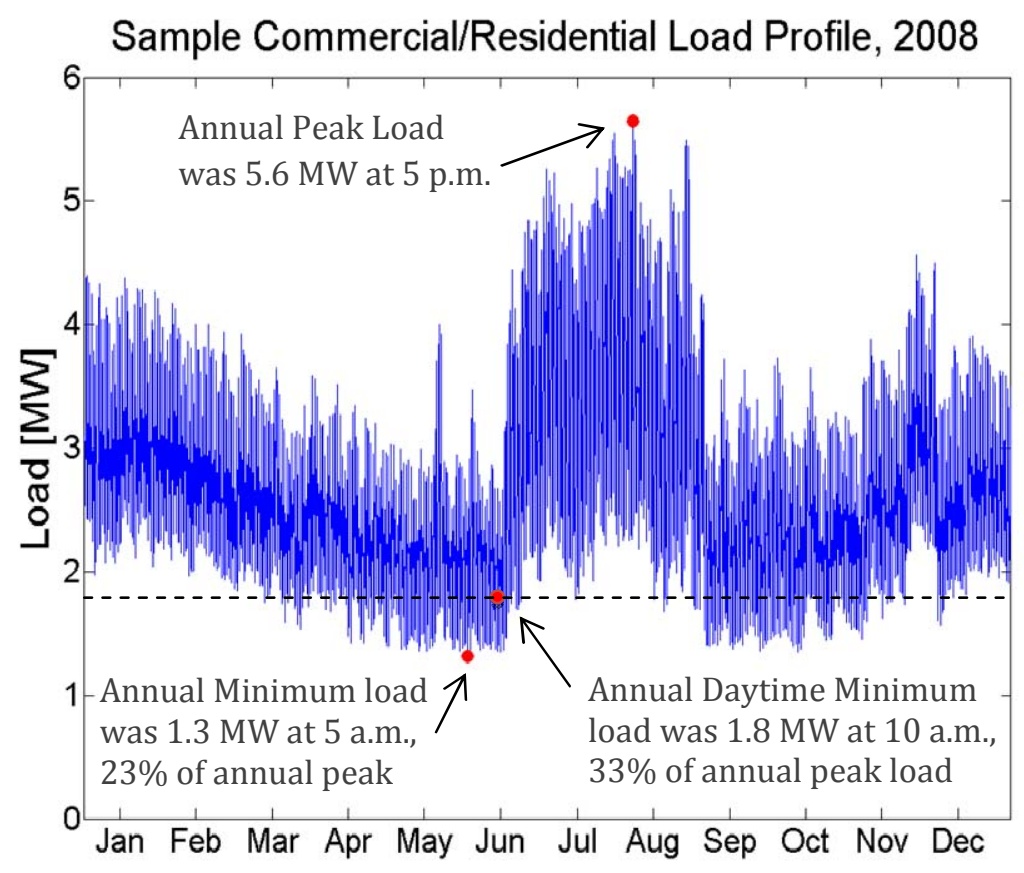

Figure 4 - This load profile indicates that minimum daytime load is significantly higher than absolute minimum load 


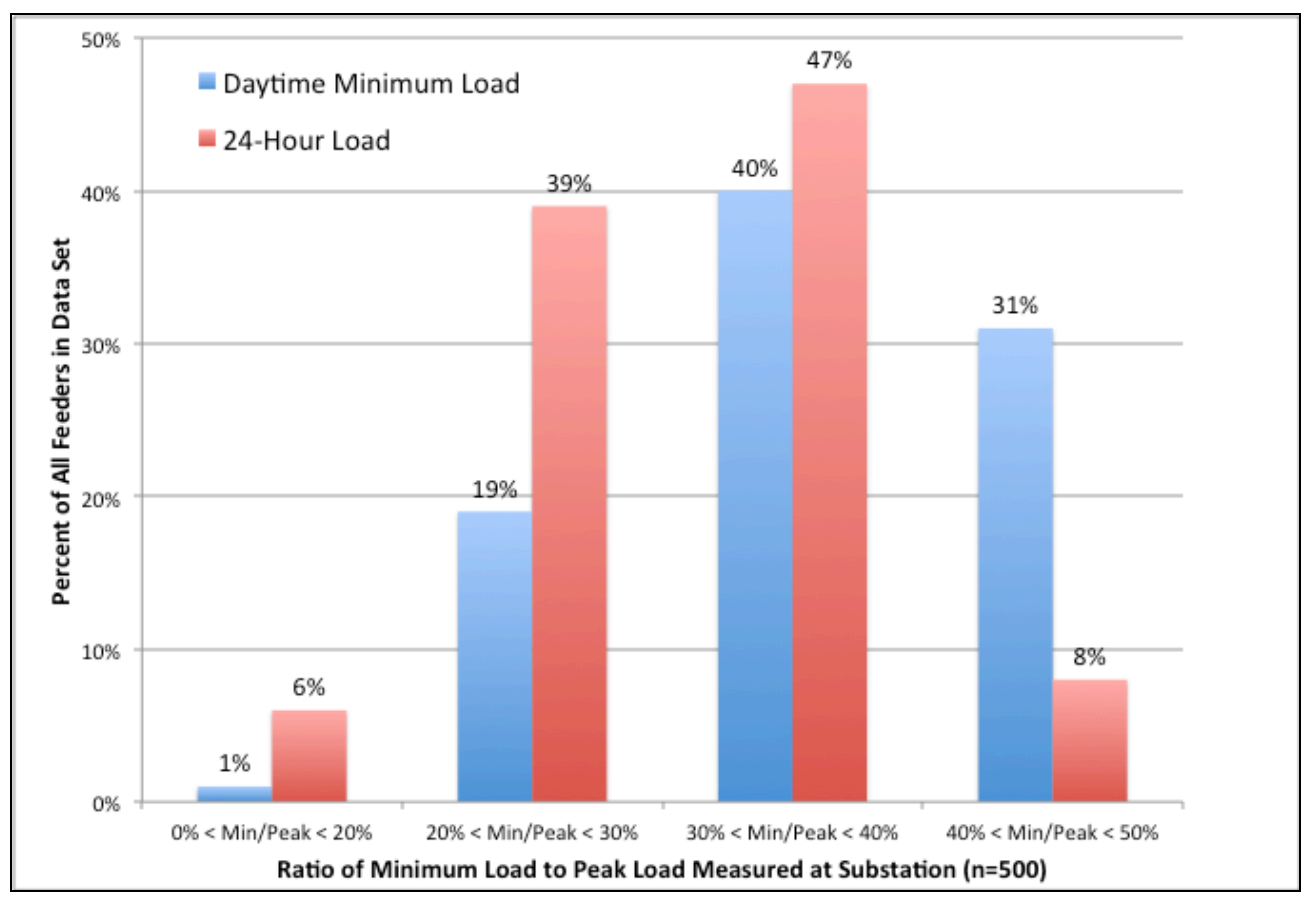

Figure 5 - Ratio of minimum load to peak load for daytime minimum load (10 a.m. -2 p.m.) and 24-hour minimum load.

\subsection{Apply Supplementary Screens}

Applying supplementary screens to identify possible technical issues, regardless of penetration level, focuses on utilizing more comprehensive analyses as part of the initial review in order to eliminate the possibility of voltage regulation issues and the creation of unintentional islands. An example of this concept is shown in Figure 6. 


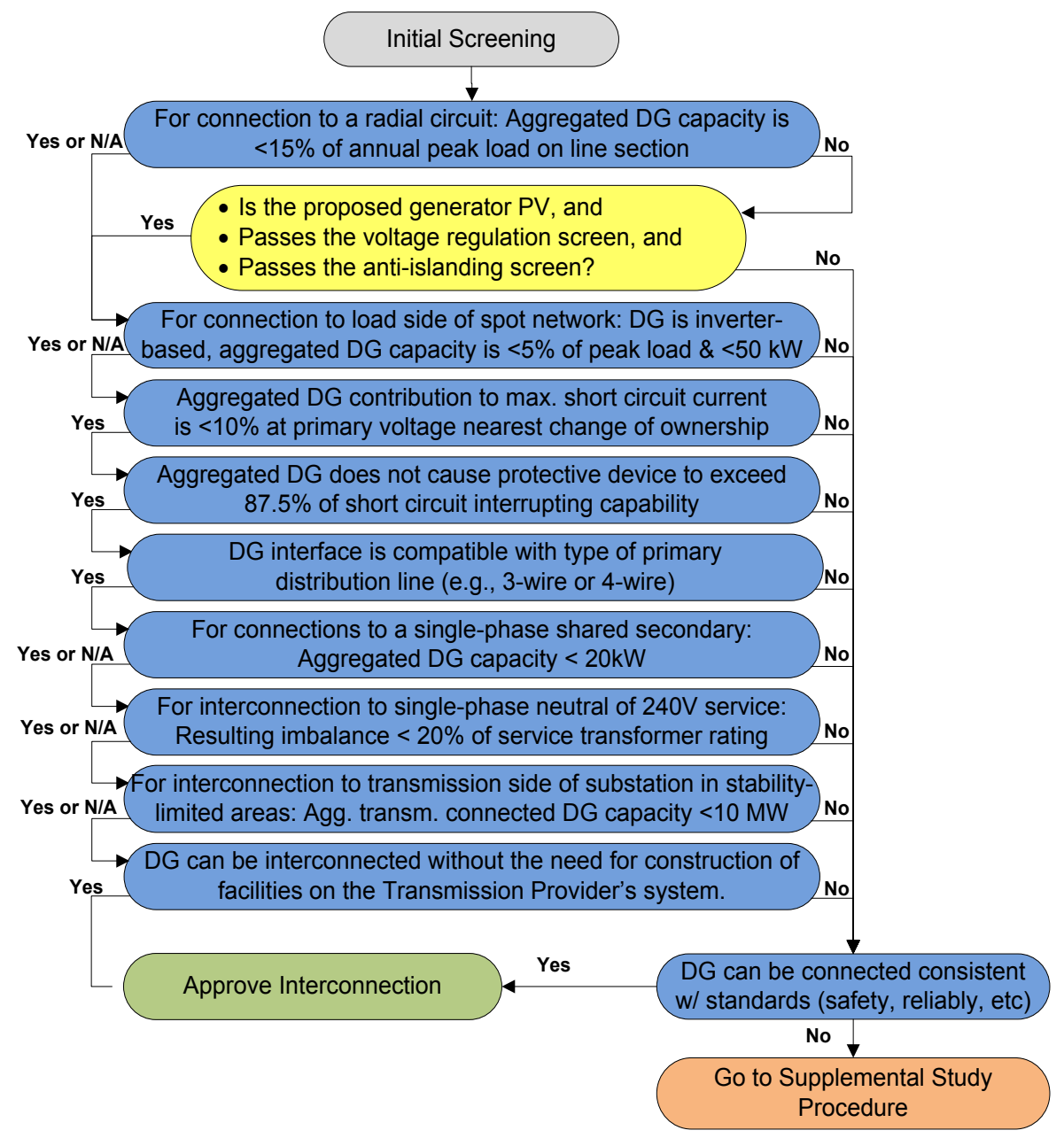

\section{Figure 6 - Modified SGIP screens to address PV interconnections regardless of penetration level}

It is important that the additional screens are effective and relatively easy to apply with well-defined costs and timeline to complete the screens, established through a transparent and open process administered by a regulatory body that takes into account stakeholder input. For example, Hawaii's revised Rule $14 \mathrm{H}^{11}$ has clear timelines for when an application must be deemed complete, examined through initial review, and processed through supplemental review. Further, the California Rule 21 Supplemental Review Guideline contains several simple procedures that can be incorporated into the initial review screen for PV systems. ${ }^{12}$ With respect to voltage regulation, a procedure similar to Figure 7 is recommended for consideration. Note that the $15 \%$ in this drawing refers to the peak export on the line section, which is different than the SGIP 15\% screen. The $15 \%$ peak export implies an instantaneous penetration level greater than $100 \%$ for these systems with export levels less than $200 \mathrm{~kW}$.

\footnotetext{
${ }^{11}$ HPUC news release http://puc.hawaii.gov/news/pressreleases/2011/2011-1129\%20PUC\%2OPress\%20Release\%20HECO\%20Rule\%2014h\%20Approval.pdf/?searchterm=rule\%2014h

12 http://www.energy.ca.gov/distgen/interconnection/model_rule.html.
} 


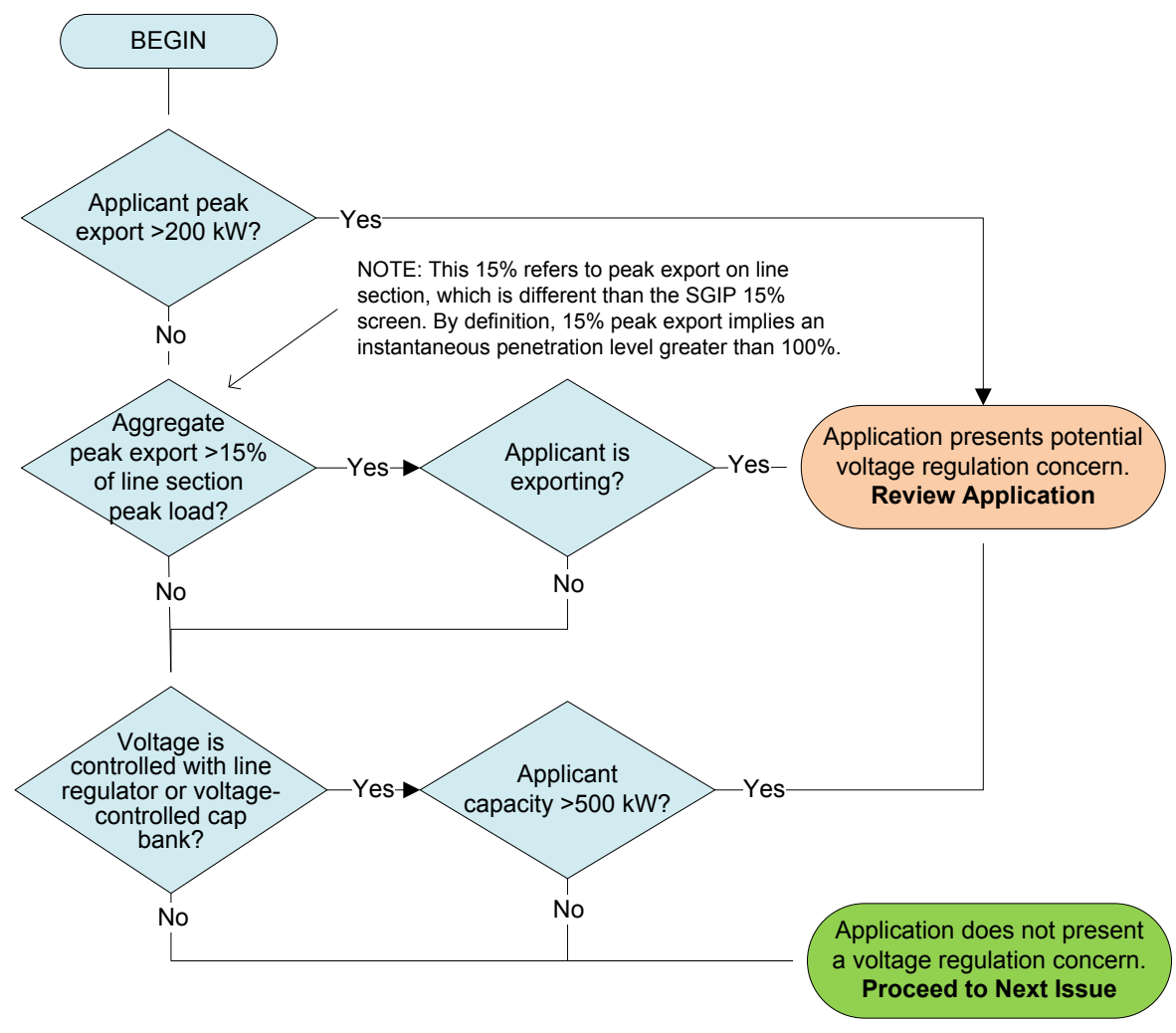

\section{Figure 7 - Possible additional screening procedure for PV systems addressing voltage issues}

Similarly for anti-islanding, Rule 21 Supplemental Review Guide contains a simple screen that can be applied as part of the initial review as seen in Figure 8. Application of the screen is more involved, but could be reasonably carried out as part of the Initial review since only a minimal amount of information is required. 


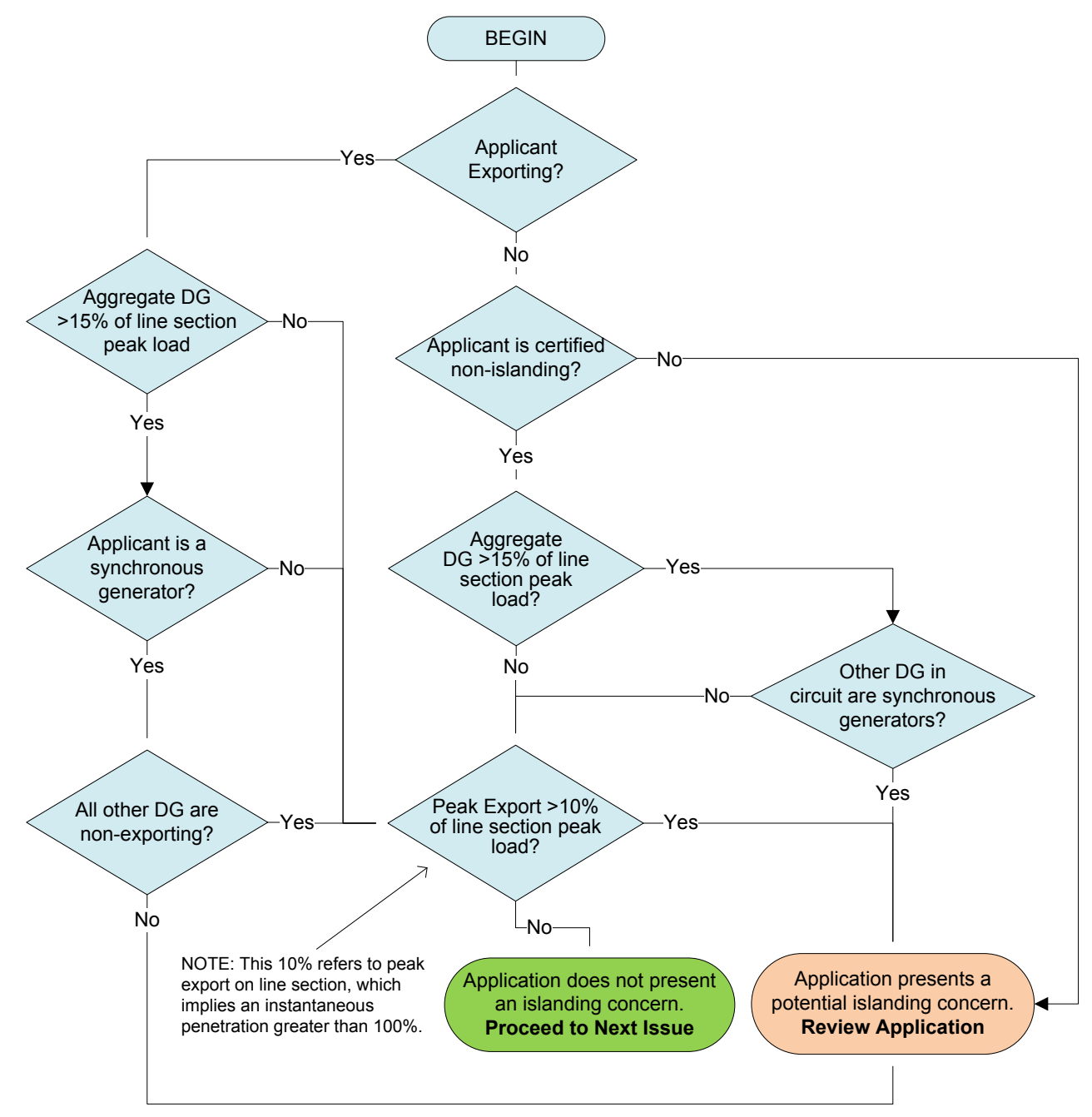

\section{Figure 8 - Possible supplemental screening procedure for PV systems addressing unintentional islanding issues}

\subsection{Utility Identified Zones of Penetration Levels}

One concept for increasing penetration criteria is to identify zones where higher penetration is acceptable. These zones would be identified by utilities through a transparent and open process administered by a regulatory body that takes into account stakeholder input, and should not exclude PV interconnection outside the zones as shown in Figure 9.

These zones would likely be located in areas closer to substations or with low-impedance conductors, thus having a lower potential for voltage abnormalities or protective system miscoordination. Figure is an example area displaying zones that allow for greater penetration and those that require further study. These zones would change over time as new installations of DG come online. One shortcoming of this conceptual drawing is the difficulty presented in measuring load, thus penetration, and how adjacent zones will affect one another. Implementing this would likely be labor-intensive, and require greater utility staffing levels. The California Energy Commission recently published a report that proposes 
several criteria for identifying project areas requiring minimal detailed studies. ${ }^{13}$ The report discusses a modeled system in which a wholesale PV project might have acceptable impact if connected in one location in a circuit, but may have significant impacts requiring mitigation or upgrades if connected in another location.

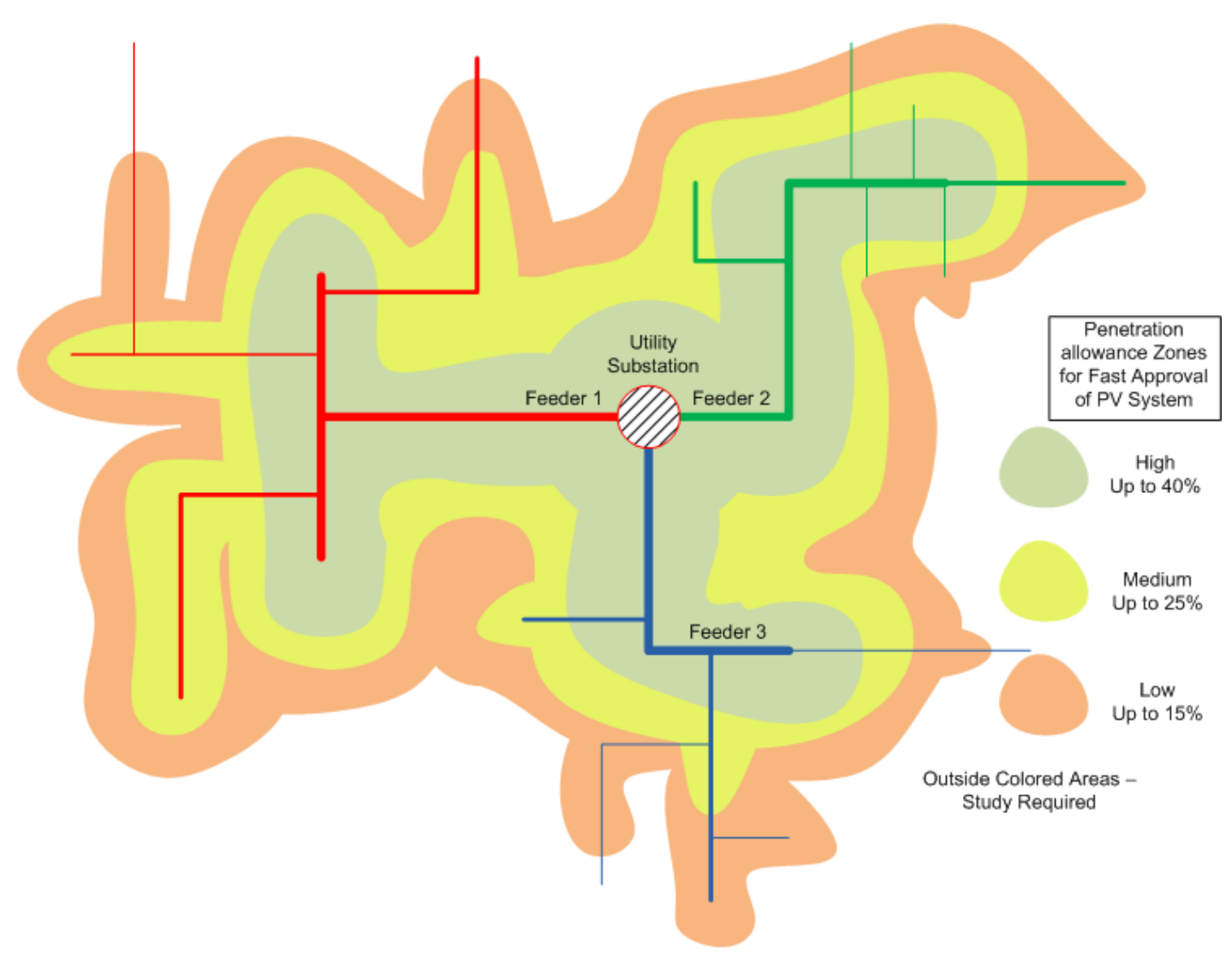

Figure 9 - An example area with zoned penetration limits

\section{Mid-Term and Long-Term Solutions}

While short-term solutions may be applied in a one-year or less time frame, there are more promising solutions to be considered that will take longer to develop and implement. Midterm solutions, for this paper, might be those that happen in the one- to five-year range, while long-term solutions are likely those beyond the five-year horizon.

\subsection{Develop Higher Accuracy Screening Metrics and Formulas}

PV penetration metrics alone are insufficient indicators of the expected distribution system level impacts from PV interconnection. One potential solution is to develop more accurate screening metrics that can be used in a revised screening process. An interconnection impact metric for each PV interconnection concern, e.g. voltage effects, unintentional islanding, and protection coordination, could be developed. These metrics are functions of multiple distribution and PV system characteristics. For example, from previous highpenetration PV integration case study data, it is known that a PV system's nameplate

${ }^{13}$ http://www.energy.ca.gov/2011publications/CEC-200-2011-014/CEC-200-2011-014.pdf 
capacity, circuit impedance, and distance from the distribution substation are key indicators of the expected voltage impacts of the PV system interconnection. A more reliable voltage impact metric can be formulated through extensive distribution system modeling using verified models that incorporate both the PV system nameplate capacity and the location of the interconnection on the distribution system. Other circuit characteristics and parameters, such as circuit voltage, conductor sizing, voltage regulation scheme, and the required service voltage range can also be considered in the development of a more reliable PV voltage impact metric. A sensitivity analysis for each considered circuit characteristic would then be performed and only the characteristics that largely determine the system impacts due to PV interconnection would be included in the final PV impact metric in order to simplify the calculation of the metric as much as possible.

The proposed PV impact metrics are more difficult to calculate than the current penetration metric (15\%) but are still calculated based on available distribution circuit and PV system parameters. The developed PV impact metrics is a set of formulas that indicate whether the impacts of an individual PV interconnection exceed a given range agreed by the utilities and regulators similar to the PV penetration metric currently under use. Since PV impact metrics are developed for each interconnection concern and each metric takes into account a number of system characteristics and parameters, the resulting PV interconnection screening process allows more safe and compatible PV system to be interconnected without a supplemental interconnection study.

\subsection{Upgrade Distribution Circuit Design for PV-Hosting Applications}

Upgrading existing distribution feeders with larger-sized (thus lower impedance) conductors, installing voltage regulation devices, and increasing operating voltages (e.g. from $4 \mathrm{kV}$ to $13.2 \mathrm{kV}$ ), are ways to maintain acceptable voltage levels and increase the PV hosting capacity of a feeder. Larger conductors and higher operating voltages allow greater levels of power delivery to loads as well as maintaining voltage levels, but there are financial impacts associated with these approaches.

New circuits designed and built in areas where there is significant PV development should be evaluated for increased conductor size and installation of voltage regulators. Existing distribution circuits can also be upgraded, but the process is often more complicated. The cost of such upgrades might be shared between utilities and PV developers, but that policy issue is not discussed in detail in this paper. Costs may range from a few thousand dollars for modifying controls for bi-directional voltage regulators, for example, to hundreds of thousands of dollars for replacing several miles of smaller conductors with larger conductors.

Capital expenditures by utilities are constrained by the availability of financial resources and limited by regulatory agencies and financial organizations. If greater expenditures are encouraged, then regulated utilities will need approval from utility commissions and by the organizations that have financial oversight over the utilities. Investor-owned utilities have specific revenue to capital investment requirements necessary to maintain stock ratings, and this could be a significant issue when considering upgrading distribution circuits. Investor-owned utilities often issue stock to raise money for capital expenditure programs that include new and rebuilt distribution circuits. Other types of utilities, such as cooperatives and municipal-owned utilities have other difficulties in paying for upgrades. 


\subsection{Deploy Inverters with Advanced Functions}

Today, the challenge involves integrating PV into the existing electrical distribution systems that were not designed for significant reverse power. Inverter grid support functions are either unavailable or unused. Future investments and application of new technologies are expected to significantly increase PV hosting capability. Although it will take time to implement, a new generation of inverters is available with advanced functions designed to interact and support the grid. Enabling these functions will involve setting up, programming, reacting to grid condition signals, and potentially implementing two-way communications with distribution system operators. Also evolving is a smart grid with more automated distribution equipment and the ability to process information fed into both a central distribution management system and dispersed management systems that will manage accordingly. Advanced communication and control will enable the future distribution systems to better coordinate settings and limits of switch, protection, and voltage control devices as conditions change. Together, advanced inverter functions and distribution automation are expected to significantly increase the PV hosting capability of the existing infrastructure.

Relative to other devices connected to utility distribution systems, PV inverters are highly capable in terms of responsiveness, controllability, processing capability, and memory. Advanced inverters and controllers will provide real-time reactive power compensation, real power curtailment, watt-voltage, and watt-frequency management. Configurable autonomous actions can support the grid during abnormal voltage or frequency conditions. Previous studies have shown that advanced inverters can mitigate voltage-related issues and potentially increase the hosting capacity of solar PV by as much as $100 \% .{ }^{14}$ This point is further illustrated in Figure 10, where the feeder voltage response is shown to improve with the use of advanced volt-VAr control.

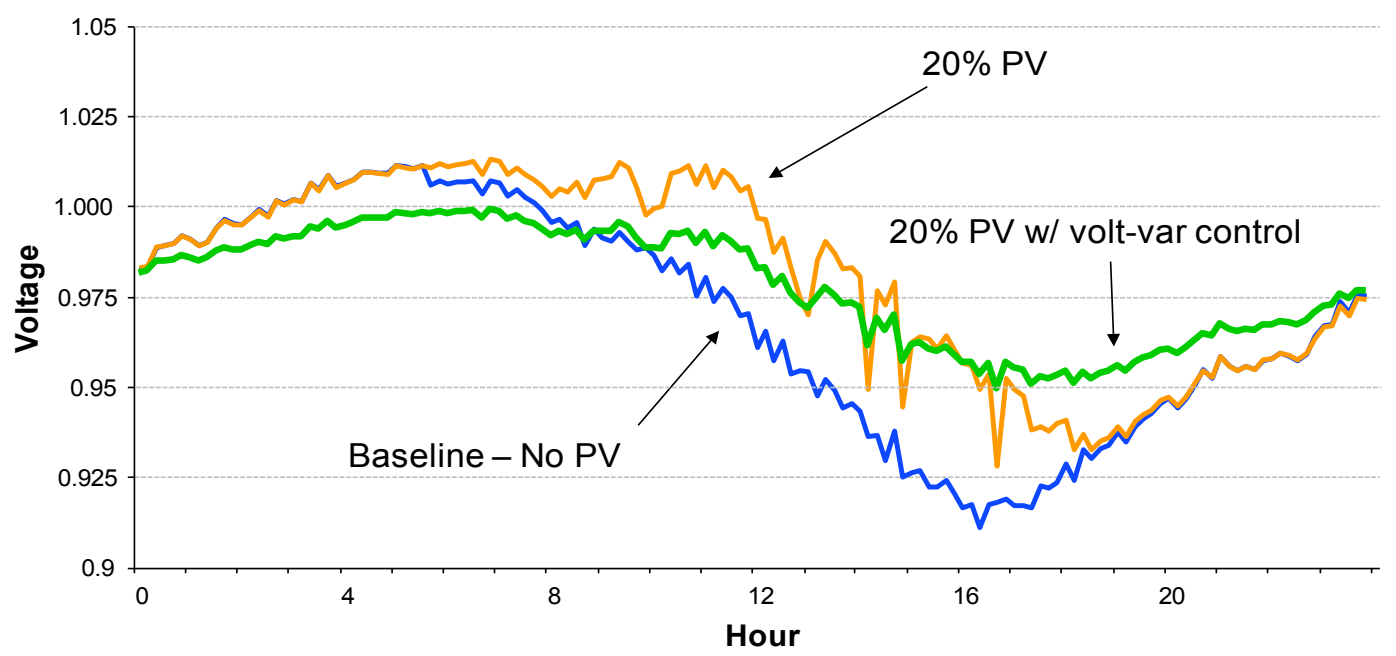

Figure 10 - Feeder voltage response with advanced VAr control ${ }^{15}$

\footnotetext{
${ }^{14}$ Braun, M., Stetz, T., Bründlinger, R., Mayr, C., Ogimoto, K., Hatta, H., Kobayashi, H., Kroposki, B., Mather, B., Coddington, M., Lynn, K., Graditi, G., Woyte, A. and MacGill, I. (2011), Is the distribution grid ready to accept large-scale photovoltaic deployment? State of the art, progress, and future prospects. Progress in Photovoltaics: Research and Applications. doi: 10.1002/pip.1204.

${ }^{15}$ Smith, J., Sunderman, W. Dugan, R., Seal, B., "Smart Inverter Volt/VAr Control Functions for High Penetration of PV on Distribution Systems", 2011 Power Systems Conference and Exposition, Phoenix, Arizona, March 2011.
} 
Other functions, such as voltage and frequency ride-through, short-term or dynamic AC voltage support, inverter response to active anti-islanding, and arc-fault detection and mitigation, can increase reliability and safety.

Taking advantage of advanced inverter functions, along with other opportunities for demand management, will require communication and control and, consequently, opportunities will evolve with a smarter distribution system. For PV inverters there will be potential to perform a large number of grid-supportive functions. The value of this functionality depends on the degree in which a grid operator can integrate PV functions with other distribution equipment.

Interconnection standards must be defined and developed before these advanced inverters are deployed in larger numbers on electric distribution systems. IEEE P1547.816 is the standard recommended practice under development that will help define how these advanced inverters will be integrated into an electric distribution system. Completion of this standard will pave the way for a future interconnection standard which will supplant IEEE 1547.17

\section{Conclusion and Next Steps}

Thousands of applications are submitted in the United States each year for PV installations and many states have aggressive renewable portfolio standards that encourage these installations. Therefore, it is critical that interconnection procedures be as streamlined as possible to avoid unnecessary interconnection studies, costs, and delays. There is an implicit expectation that existing interconnection procedures will evolve over time to reflect changes in standards, technology, and practical experience. Modifications to interconnection screens and procedures must have a focus on maintaining or improving safety and reliability, as well as reducing costs and improving expediency of the interconnection process.

Three short-term approaches have been presented for consideration. The first approach suggests utilizing PV-specific screening criteria that would utilize minimum daytime load for a circuit rather than absolute minimum load or a percentage of peak load. The second approach is to apply additional screens to evaluate potential voltage or unintentional island problems, regardless of penetration levels. The third approach would increase penetration levels in specific areas or zones based on substation location, circuit design, and existing DG. These three conceptual approaches may be considered as solution frameworks for increasing levels of PV deployment.

Mid-term and long-term solutions require close cooperation between regulatory agencies, electric utilities, national laboratories, DOE, EPRI, equipment manufacturers, and PV developers. These solutions ultimately produce straightforward approaches to understand how much PV can be deployed on a circuit, and at what locations, while maintaining a focus on safety, reliability and cost. Modeling, observation, testing, failure analysis, success analysis, and technology development is attainable through mutual cooperation and a focus on success.

\footnotetext{
${ }^{16}$ For additional information see http://grouper.iee.org/groups/scc21/1547.8/1547.8_index.html.

${ }^{17}$ For additional information see http://grouper.ieee.org/groups/scc21/1547/1547_index.html.
} 